\title{
Strength properties of cement-based composites with CFBC fly ash and coal-fired fly ash
}

\author{
Maochieh Chi ${ }^{1, a}$, Jiang-Jhy Chang ${ }^{2, b}$ and Kuo-Lien Chen ${ }^{2, c}$ \\ ${ }^{1}$ WuFeng University, 117, Sec 2, Chiankuo Rd, Minhsiung, Chiayi County 62153, Taiwan \\ ${ }^{2}$ National Taiwan Ocean University, 2 Pei-Ning Road, Keelung , 20224, Taiwan \\ a jackchi@wfu.edu.tw, ${ }^{b}$ jic@mail.ntou.edu.tw, ${ }^{\circ}$ 01.junfou@gmail.com \\ ${ }^{*}$ Corresponding author: Maochieh Chi
}

\begin{abstract}
Keywords: Strength properties, CFBC Fly Ash, Coal-fired Fly Ash.
Abstract. This study is to investigate the strength properties of cement-based composites with circulated fluidized bed combustion (CFBC) fly ash and coal-fired fly ash. Ten different blended cements were prepared to cast mortar specimens. The compressive strength, tensile strength, and flexural strength were conducted and the results were compared. Test results show that the mixtures with $10 \%$ CFBC fly ash as cement replacement have better strength properties. Meanwhile, with a fixed replacement of $10 \%$ CFBC fly ash, the amounts of cement replacement by coal-fired fly ash was recommended to no more than $20 \%$ based on the present results.
\end{abstract}

\section{Introduction}

Circulating fluidized bed combustion (CFBC) is an advanced, clean, and reliable coal firing technology for power generation, which has met the environmental requirement for large reductions in $\mathrm{SO}_{2}$ and $\mathrm{NO}_{\mathrm{x}}$ emissions $[1,2]$ and caught increasing attention. CFBC fly ash is an industrial waste from CFBC boiler of electric power plant, and have such a high sulfur content that would result in a great risk of destructive expansion when used in building materials[3]. In addition, CFBC fly ash meets neither North American nor Europen standards for components or additives in concrete[4]. Thus, the use of CFBC fly ash remains limited in cement and concrete. Though CFBC fly ash is not a good supplementary cementitious material for Portland cement and concrete, several papers reported that CFBC fly ash can be used to in developing controlled low strength material mixtures[5].

Chi and Huang[6] pointed out that CFBC fly ash has a positive effect on compressive strength and splitting tensile strength. Freidin [7] found that a fly ash with high $\mathrm{f}-\mathrm{CaO}$ and high $\mathrm{SO}_{3}$ content has good self-cementitious properties, the compressive strength develops gradually and has the lowest compressive strength as the specimens curing in the open air. Sheng et al. [8] indicated that the CFBC fly ash had a little effect on compressive strength when its amount was less than 20\%. Zhang and Qiu [9] have manufactured the cement with CFBC fly ash and PFA which can reach about 32.5 to $42.5 \mathrm{MPa}$ of compressive strength at the age of 28 days. Chen et al. [10] found that the most reasonable dosages of CFBC fly ash were $70 \%$ and the finer CFBC fly ash is better to improve the compressive strength. In this study, CFBC fly ash and coal fly ash were used in Portland cement to investigate the strength properties of blended cement mortars.

\section{Experimental program}

Materials. Three kinds of materials, Type I ordinary Portland cement (OPC) conforming to ASTM $\mathrm{C} 150$, circulated fluidized bed combustion (CFBC) fly ash and Class F coal-fired fly ash with the physical properties and chemical compositions of these materials listed in Table 1 were used in this study. CFBC fly ash and coal fly ash were obtained from the Mailiao Six Light Naphtha Cracker Plant, located in the Yunlin county of Taiwan. CFBC fly ash of gray-and-white powder passing No. 200 $(75 \mu \mathrm{m})$ accounts for about $86 \%$ of the particles. The specific gravity of CFBC fly ash is $2.75-2.85$. The blaine specific surface area was $2880 \sim 3050 \mathrm{~cm}^{2} / \mathrm{g}$. Coal-fired fly ash was used for partial cement replacement by weight. The specific gravity of coal-fired fly ash is 2.39 . The blaine specific surface area 
was $4050 \mathrm{~cm}^{2} / \mathrm{g}$. River sand with its fineness modulus, bulk density and absorption of $2.33,2580 \mathrm{~kg} / \mathrm{m}^{3}$ and $2.94 \%$, respectively, was used as a fine aggregate.

Table 1 Physical properties and chemical composition of raw materials (\%wt)

\begin{tabular}{lccc}
\hline Chemical compositions (\%) & OPC & CFBC fly ash & Coal-fired fly ash \\
\hline Specific gravity & 3.15 & 2.76 & 2.39 \\
Blaine fineness, $\mathrm{cm}^{2} / \mathrm{g}$ & 3450 & 3000 & 2370 \\
Calcium oxide, $\mathrm{CaO}$ & 63.8 & 56.80 & 1.94 \\
Sulfur trioxide, $\mathrm{SO}_{3}$ & 2.20 & 32.40 & 0.57 \\
Silicon dioxide, $\mathrm{SiO}_{2}$ & 20.6 & 5.22 & 56.66 \\
Ferric oxide, $\mathrm{Fe}_{2} \mathrm{O}_{3}$ & 3.20 & 0.58 & 7.56 \\
Aluminum oxide, $\mathrm{Al}_{2} \mathrm{O}_{3}$ & 5.40 & 2.21 & 23.97 \\
Magnesium oxide, $\mathrm{MgO}$ & 1.98 & 2.06 & 0.93 \\
Loss on ignition, L.O.I. & 1.00 & 7.83 & 2.76 \\
\hline
\end{tabular}

Mixes design and specimens preparation. Mixing of Ordinary Portland cement (OPC) mortars and blended cement mortars with $536 \mathrm{~kg}$ of binder per cubic meter according to ASTM C192 was designed. The liquid/binder ratio was kept at a constant of 0.5 . Ten different mixtures were prepared with varying proportions of OPC, CFBC fly ash, and coal-fired fly ash to produce mortar specimens. The mix proportions are shown in Table 2. The specimens were cast and kept in steel molds for 24 hours, and then they were demolded and moved into a curing room at relative humidity of $80 \% \mathrm{RH}$ and $25^{\circ} \mathrm{C}$ until testing. The specimens were tested in triplicate sets until the time of testing.

Table 2 Mix proportions of the blended cement mortar specimens

\begin{tabular}{ccccccc}
\hline Mix no.* & $\begin{array}{c}\text { Cement/ Coal fly } \\
\text { ash/CFBC fly ash } \\
\text { (mass ratio) }\end{array}$ & $\begin{array}{c}\text { Water } \\
\left(\mathrm{kg} / \mathrm{m}^{3}\right)\end{array}$ & $\begin{array}{c}\text { Fine } \\
\text { aggregate } \\
\left(\mathrm{kg} / \mathrm{m}^{3}\right)\end{array}$ & $\begin{array}{c}\text { Cement } \\
\left(\mathrm{kg} / \mathrm{m}^{3}\right)\end{array}$ & $\begin{array}{c}\text { Coal fly ash } \\
\left(\mathrm{kg} / \mathrm{m}^{3}\right)\end{array}$ & $\begin{array}{c}\text { CFBC fly ash } \\
\left(\mathrm{kg} / \mathrm{m}^{3}\right)\end{array}$ \\
\hline OPM & $10 / 0 / 0$ & 268 & 1474 & 536 & 0 & 0 \\
F0C1 & $9 / 0 / 1$ & 268 & 1380 & 483 & 0 & 54 \\
F0C2 & $8 / 0 / 2$ & 268 & 1374 & 429 & 0 & 107 \\
F0C3 & $7 / 0 / 3$ & 268 & 1368 & 375 & 0 & 161 \\
F1C1 & $8 / 1 / 1$ & 268 & 1360 & 429 & 54 & 54 \\
F2C1 & $7 / 2 / 1$ & 268 & 1340 & 375 & 107 & 54 \\
F4C1 & $5 / 4 / 1$ & 268 & 1300 & 268 & 214 & 54 \\
F1C2 & $7 / 1 / 2$ & 268 & 1354 & 375 & 54 & 107 \\
F2C2 & $6 / 2 / 2$ & 268 & 1334 & 322 & 107 & 107 \\
\hline
\end{tabular}

${ }^{*}$ Within mixture designation FxCy, $\mathrm{x}$ represents the level of replacement (in wt\%) of coal-fired fly ash and y represents the level of replacement (in wt\%) of CFBC fly ash.

Methods. This study is to investigate the strength properties of cement-based composites with CFBC fly ash and coal-fired fly ash. Compressive strength, tensile strength, and flexural strength were conducted and the results were compared. For each mixture, three 50x50x50 mm cubic specimens were prepared and tested for each mixture at the ages of 7, 14, 28 and 91 days, respectively.

\section{Results and discussion}

Compressive strength. The compressive strengths of OPM and blended cement specimens with various CFBC fly ash replacement rates at the ages of 7, 14, 28 and 91 curing days are shown in Figure 1. It shows that OPM specimen has the highest compressive strength than any others at the early ages. The compressive strength of all specimens increases with an increasing age. At the age of 14 days, the compressive strength of the specimen with $10 \%$ CFBC fly ash (F0C1) is close to that of OPM 
specimen. After 28 days, the specimen F0C1 has the highest compressive strength, with $54.9 \mathrm{MPa}$ of the compressive strength, followed the specimen OPM, with 51.0 MPa, and then the specimen F0C2, with $36.1 \mathrm{MPa}$. Specimen F0C3 is on the other end of the scale, with $30.6 \mathrm{MPa}$. It indicates that $10 \%$ cement replacement by CFBC fly ash could be regarded as the optimum range. Figure 2 presents the compressive strengths of OPM and blended cement specimens with various coal-fired fly ash and CFBC fly ash replacement rates at the ages of 7, 14, 28 and 91 curing days. It can be seen that OPM specimen has the highest compressive strength than any others at all ages. With the fixed CFBC fly ash of $10 \%$, the specimen with coal-fired fly ash of $10 \%$ (F1C1) had the highest compressive strength, followed the specimen $\mathrm{F} 2 \mathrm{C} 1$, and then the specimen $\mathrm{F} 1 \mathrm{C} 2$. The specimen with higher amounts of CFBC fly ash and coal-fired fly ash showed the lower compressive strength at all ages. The compressive strength decreases with the increase of cement replacement. The compressive strength is affected by the cementitious materials, in particular the content of cement. The decrease in compressive strength for blended cement concrete is due to the reduction of the cement content in the mixture and too much $\mathrm{Ca}(\mathrm{OH})_{2}$ produced from the reaction of free lime with water which is unfavorable to the mechanical properties of cement.

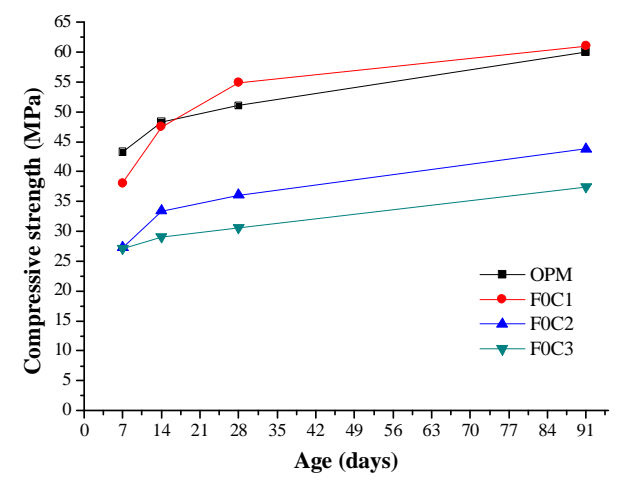

Figure 1 Effect of CFBC fly ash replacement rate on compressive strength

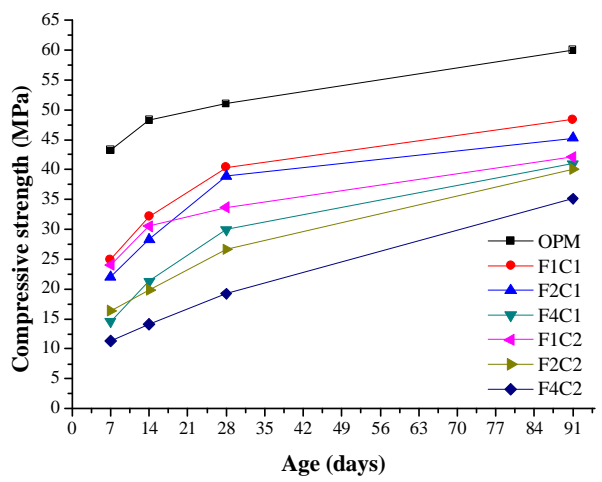

Figure 2 Effect of coal-fired fly ash and CFBC fly ash replacement rate on compressive strength

Tensile strength. The tensile strengths of OPM and blended cement specimens with various CFBC fly ash replacement rates at the ages of 7, 14, 28 and 91 curing days are shown in Figure 3. It shows that OPM specimen has the highest tensile strength than any others at all ages. The tensile strength of blended cement specimens decreases with an increasing CFBC fly ash replacement rate. At the age of 91 days, the tensile strength of the specimen with $10 \%$ CFBC fly ash (F0C1) is close to that of OPM specimen. Figure 4 shows the tensile strengths of OPM and blended cement specimens with various coal-fired fly ash and CFBC fly ash replacement rates at the ages of 7, 14, 28 and 91 curing days. The tensile strength of specimen increases sharply at early ages. After 28 days, the rise of tensile strength is slight except the specimens with $40 \%$ coal-fird fly ash replacement. It shows that the tensile strength of specimens with $40 \%$ coal-fird fly ash replacement (F4C1 and $\mathrm{F} 4 \mathrm{C} 2)$ increases with the increasing ages continuously after 28 days. Foe example, the specimen with $40 \%$ coal-fired fly ash and $20 \%$ CFBC fly ash (F4C2) has the lowest tensile strenth at early ages, however, the tensile strength of specimen F4C2 is close to that of OPM at the age of 91 days. Meanwhile, the specimen with $40 \%$ coal-fired fly ash and $10 \%$ CFBC fly ash (F4C1) has the highest tensile strength than any others at the age of 91 days. For specimens with a fixed amount of CFBC fly ash, the tensile strength has not a significant difference with $10 \%$ and 20\% coal-fired fly ash replacement. As shown in Figure 4, the tensile strength development of specimens $\mathrm{F} 1 \mathrm{C} 1$ is similar to specimen $\mathrm{F} 2 \mathrm{C} 1$. Likely, the tensile strength development of specimen $\mathrm{F} 1 \mathrm{C} 2$ is almost the same as that of specimen $\mathrm{F} 2 \mathrm{C} 1$.

Flexural strength. The flexural strengths of OPM and blended cement specimens with various CFBC fly ash replacement rates at the ages of 7, 14, 28 and 91 curing days are shown in Figure 5. At the age of 7 days, OPM specimen has the highest flexural strength than any others. At the age of 14 days, the flexural strength of the specimen F0C1 is close to that of OPM specimen. After 28 days, the specimen 
F0C1 has the highest compressive strength, with 6.5 MPa of the flexural strength, followed the specimen OPM, with 6.0 MPa, and then the specimen F0C2, with 3.1 MPa. Specimen F0C3 is on the other end of the scale, with 3.0 MPa.

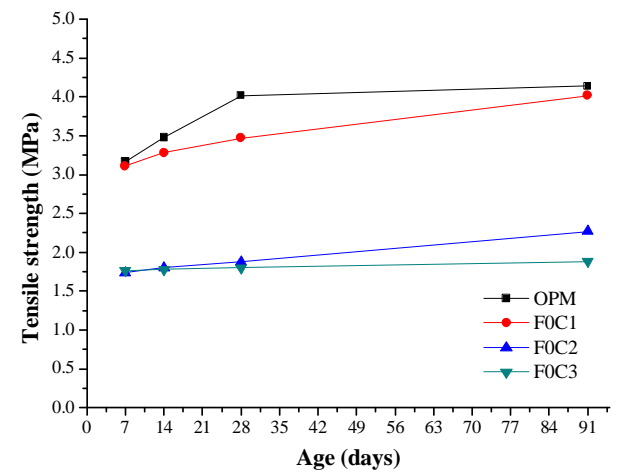

Figure 3 Effect of CFBC fly ash replacement rate on tensile strength

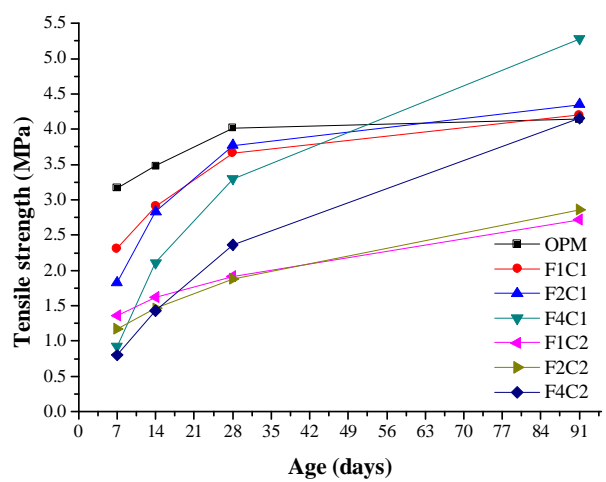

Figure 4 Effect of coal-fired fly ash and CFBC fly ash replacement rate on tensile strength

Figure 6 shows the flexural strengths of OPM and blended cement specimens with various coal-fired fly ash and CFBC fly ash replacement rates at the ages of 7, 14, 28 and 91 curing days. It can be seen that the flexural strength of specimens with $10 \%$ is higher than that of OPM specimen at the age of 91 days. Meanwhile, the flexural strength decreases with an increase of coal-fired fly ash replacement.

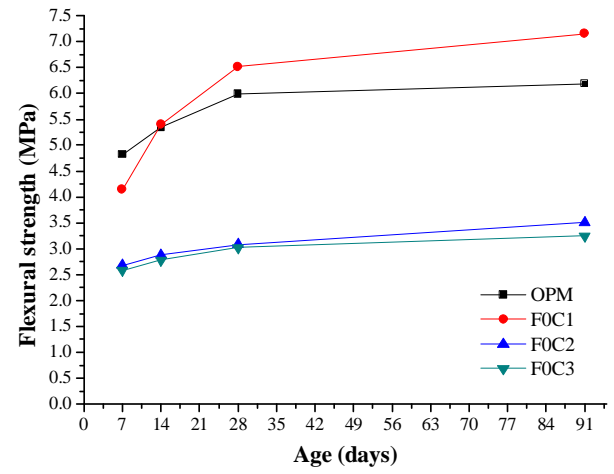

Figure 5 Effect of CFBC fly ash replacement rate on flexural strength

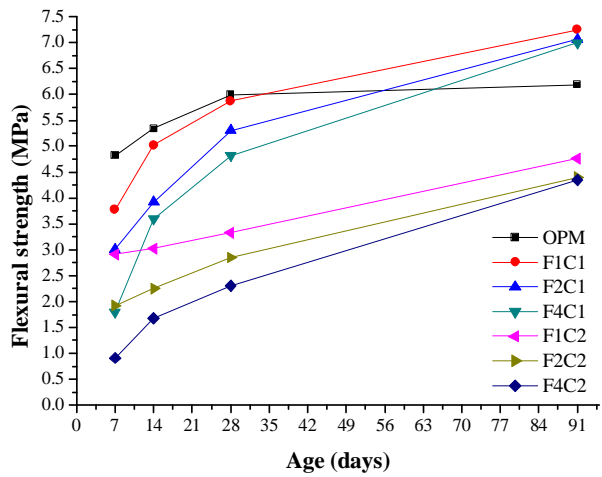

Figure 6 Effect of coal-fired fly ash and CFBC fly ash replacement rate on flexural strength

\section{Conclusions}

This study investigates the strength properties of cement-based composites with CFBC fly ash and coal-fired fly ash. On the basis of test results, the following conclusions should be drawn:

(1) The mixtures with $10 \%$ CFBC fly ash as cement replacement have better strength properties.

(2) With a fixed replacement of $10 \%$ CFBC fly ash, the amounts of cement replacement by coal-fired fly ash was recommended to no more than $20 \%$ based on the present results.

\section{References}

[1] H.A. Nguyen, T.P. Chang, J.-Y. Shih, and C.T. Chen: Constr Build Mater Vol. 91 (2015) p. 208.

[2] X. Fu, Q. Li, J. Zhai, G. Sheng, and F. Li: Cem Concr Compos Vol.30 (2008) p. 220.

[3] Z. Zhang, J. Qian, C. You, and C. Hu: Constr Build Mater Vol.35 (2012): p. 109.

[4] Q. Li, , H. Xu, F. Li, P. Li, L. Shen, and J. Zhai: Fuel Vol.97(2012) p. 366.

[5] C. Shon, , D. Saylak, and D.G. Zollinger: Constr Build Mater Vol.23(2009) p. 2062.

[6] M. Chi, and R. Huang: Cem Concr Compos Vol.45 (2014)p. 148.

[7] C. Freidin: Cem concr res Vol.28 (1998) p. 829. 
[8] G. Sheng, , Q. Li, J. Zhai, and F. Li: Cem concr res Vol.37 (2007) p. 871.

[9] H.Zhang, and K. Qiu: 14th International Conference on FBC (1997) Vancouver: ASME.

[10]X.Chen, , Y. Yan, Y. Liu, and Z. Hu,: Constr Build Mater Vol. 54 (2014) p. 137. 